\title{
Adesão e aceitabilidade de cardápios da alimentação escolar do ensino fundamental de escolas de zona rural
}

\author{
Adhesion and acceptability of elementary school menus in rural schools
}

\section{Chirle de Oliveira Raphaelli*, Luciana Dieguez Ferreira Passos², Shanda de Freitas Couto ${ }^{3}$, Elizabete Helbig², Samanta Winck Madruga ${ }^{2}$}

\author{
1 Universidade Federal de Pelotas (UFPEL), Programa de Pós-graduação em Educação Física, Pelotas/RS - Brasil \\ 2 Universidade Federal de Pelotas (UFPEL), Programa de Pós-graduação em Nutrição e Alimentos, Pelotas/RS - Brasil \\ ${ }^{3}$ Universidade Federal do Pampa (UNIPAMPA), Itaqui/RS - Brasil
}

\section{*Corresponding Author}

Chirle de Oliveira Raphaelli, Universidade Federal de Pelotas (UFPEL), Escola Superior de Educação Física, Rua Luís de Camões, 625, Três Vendas, CEP: 96055-630, Pelotas/RS - Brasil, e-mail: chirleraphaelli@hotmail.com

Cite as: Adhesion and acceptability of elementary school menus in rural schools. Braz. J. Food Technol., v. 20, e2016112, 2017.

Received: Sept. 01, 2016; Accepted: Dec. 09, 2016

\section{Resumo}

A alimentação adequada e saudável em idade escolar é de fundamental importância, pois auxilia no crescimento, no desenvolvimento, na aprendizagem e no rendimento escolar. A alimentação escolar deve atender às necessidades nutricionais dos escolares e suas preferências alimentares. Objetivou-se avaliar a adesão e a aceitabilidade dos cardápios da alimentação escolar de município da zona rural. Um estudo transversal foi realizado em escolas municipais de Barão do Triunfo-RS, com 240 alunos, da pré-escola à oitava série. Foi aplicada a Escala Hedônica Facial e Verbal, e avaliados os índices de adesão e aceitação dos alunos com relação aos cardápios da alimentação escolar. A frequência da votação por meio da escala hedônica mostrou que $56,32 \%$ dos alunos gostaram extremamente da alimentação escolar e $22,42 \%$ gostaram moderadamente. A média de adesão dos cardápios nas escolas foi de $86,44 \%(D P \pm 9,02)$ e a média de aceitação dos alunos em relação aos cardápios foi de 90,64\% ( $D P \pm 8,79$ ). Observou-se que, ao se compararem os cardápios, os lanches obtiveram médias significativamente maiores no índice de adesão e de aceitabilidade em relação às refeições. Os índices de adesão e aceitação mostraram-se adequados em escolas da zona rural. É necessário implementar ações de educação alimentar e nutricional para valorizar a alimentação servida na escola.

Palavras-chave: Alimentação escolar; Cardápio; Política pública; Satisfação do consumidor.

\section{Summary}

Proper and healthy eating in school age children is of fundamental importance because it assists in the growth development, learning and school performance. School meals should meet the nutritional needs of school children and their food preferences. The objective of this study was to evaluate the adhesion and acceptability of school meals menus in a rural municipality, specifically that of Barão do Triunfo, RS, Brazil, using a cross-sectional study in public schools with 240 students from preschool to eighth grade. A facial and verbal hedonic scale was applied to evaluate the adhesion rates and student acceptability in relation to the school meals menus. The frequency of voting using the hedonic scale showed that $56.32 \%$ of the students liked the school meals a lot and $22.42 \%$ liked them moderately. The average adhesion to the school menus was 86.44\% (SD \pm 9.02 ) and student acceptance in relation to the menus was $90.64 \%$ (SD \pm 8.79 ). It was observed that when comparing the menus, the snacks had significantly higher means on the adhesion index and acceptability in relation to the meals. The adhesion and the acceptability rates were shown to be suitable for rural schools, but food and nutrition education activities must be implemented to give value to the food served at school.

Keywords: School feeding; Menu; Public policy; Consumer behaviour. 


\section{Introdução}

A alimentação adequada e saudável de crianças e adolescentes em idade escolar é de fundamental importância, pois contribui para o crescimento, o desenvolvimento, a aprendizagem e o rendimento escolar, além de ajudar na formação de hábitos alimentares saudáveis. Diante disso, o Programa Nacional de Alimentação Escolar (PNAE) é uma importante intervenção governamental federal na suplementação alimentar da população escolar, sendo uma das mais antigas e permanentes no âmbito das políticas social, assistencial e alimentar (SPINELLI; CANESQUI, 2002).

Em países desenvolvidos, o caráter dos programas de fornecimento de alimentação aos estudantes não mostra objetivos assistencialistas (ABREU, 1995). Diferentemente, o PNAE, em sua proposta inicial, apresentava tal característica (PEIXINHO, 2013). Porém, ao longo dos anos, passou por mudanças significativas no âmbito de sua execução (WALTER; CHAIM, 2009) e, com isso, o emprego da alimentação saudável e adequada, a inclusão da educação alimentar e nutricional no processo de ensino e aprendizagem, e o apoio ao desenvolvimento sustentável regional estão entre as principais diretrizes atuais do programa (BRASIL, 2013).

Em 1988, com a promulgação da Constituição Federal, foi assegurado o direito à alimentação escolar para todos os alunos do Ensino Fundamental (BRASIL, 1988). Em 2015, o programa atendeu, durante 200 dias letivos, a 41,5 milhões de escolares por dia, com um investimento de 3,76 milhões de reais anuais (BRASIL, 2016). Atualmente, visa atender às necessidades nutricionais dos alunos durante o período escolar, contribuir para a redução dos índices de evasão, promover hábitos alimentares saudáveis, além de estimular o desenvolvimento da economia local (MUNIZ; CARVALHO, 2007; BRASIL, 2013).

Contrapondo-se a essas necessidades, Martins et al. (2004) verificaram, em escolas de Piracicaba-SP, uma aceitabilidade da alimentação escolar regular, mostrando aceitação elevada para algumas preparações (acima de 90\%) e adesão muito baixa e diferenciada em relação aos horários de oferta da alimentação: cerca de $80 \%$ dos escolares não aderiam às refeições nos horários da entrada e 53\% não aderiam à refeição do intervalo.

Em 2009, a sanção da Lei n. ${ }^{\circ} 11.947$ trouxe novos avanços para o programa, como a extensão para toda a rede pública de educação básica e de jovens e adultos, e o estímulo ao desenvolvimento sustentável, com a garantia de que 30\% dos repasses financeiros seriam investidos na aquisição de produtos da agricultura familiar, com prioridade para produtos orgânicos ou ecológicos. Os cardápios, elaborados pelo nutricionista responsável técnico pela alimentação escolar, são compostos de gêneros alimentícios básicos, respeitando as referências nutricionais, os hábitos alimentares, a cultura e a tradição alimentar da localidade, a sazonalidade e a diversificação agrícola da região, e devem estar em conformidade com a faixa etária e o estado de saúde do escolar (BRASIL, 2009a).

A destinação de recursos financeiros do Programa para aquisição de alimentos de famílias agricultoras e empresas familiares rurais aumenta a oferta de produtos frescos e in natura, especialmente frutas e hortaliças, nos cardápios escolares (SIDANER et al., 2013). Para o sucesso desta inserção, o cardápio deve ser aceito pelos escolares, sendo que a escola, assim como a família, tem papel essencial na formação de hábitos alimentares saudáveis (RAMOS, 2011; SOUSA et al., 2015).

Os cardápios praticados frequentemente, os alimentos ou as preparações novas devem ser avaliados quanto à sua aceitação por meio de testes de aceitabilidade (BRASIL, 2009b, 2013). A aceitação de alimentos é influenciada por vários fatores, como a familiaridade com a comida, que resulta de experiências dos indivíduos com cada alimento, mostrando-se necessária a exposição a um determinado alimento diversas vezes, com diferentes preparações, para que crianças de quatro a cinco anos possam atingir mudanças definitivas em sua dieta (SULLIVAN; BIRCH, 1994; CERVATO-MANCUSO et al., 2013).

Considerando-se a importância da alimentação escolar, a aceitação ou a recusa de um determinado alimento ou cardápio servido nas escolas são fatores que, quando aferidos por meio de métodos específicos, possibilitam avaliar a qualidade da alimentação oferecida aos escolares. Assim, um dos procedimentos para o controle desta qualidade é o teste de aceitabilidade (BRASIL, 2009b).

Esse instrumento avalia se os cardápios elaborados e/ou os novos alimentos e preparações estão sendo bem aceitos pelos escolares, de modo a evitar o desperdício e verificar a qualidade do serviço prestado pelas escolas em relação ao fornecimento da alimentação escolar (CECANE, 2010). O teste de aceitabilidade é ainda utilizado para avaliar se os cardápios já praticados estão sendo repetitivos a ponto de os escolares já não mais aceitá-los (BRASIL, 2009a; CECANE, 2010).

$\mathrm{Na}$ literatura, verifica-se escassez de informações e mostram-se poucos os estudos que avaliam a adesão e a aceitabilidade da alimentação escolar em escolares de comunidades da zona rural, e se esta alimentação fornecida se apresenta em conformidade com a padronização estabelecida por tal programa. Com base nessas informações e considerando-se que o fornecimento de uma alimentação escolar deve atender, além das necessidades nutricionais, às preferências alimentares dos escolares, este estudo teve como objetivo avaliar a adesão aos cardápios da alimentação escolar e a aceitabilidade dos escolares em relação aos alimentos servidos em duas 
escolas da zona rural da rede municipal de educação de Barão do Triunfo-RS.

\section{Materiais e métodos}

Foi realizado estudo transversal em duas escolas municipais da zona rural da rede de educação de Barão do Triunfo, município localizado na região carbonífera do Estado do Rio Grande do Sul, com território de 437 km² e uma população de 6.924 habitantes (IBGE, 2010). O município conta com oito escolas municipais localizadas na zona rural e uma estadual, na zona urbana. Conforme dados de 2010, havia 957 escolares de Ensino Fundamental matriculados na Rede Municipal de Educação (INEP, 2009). Para a escolha das duas escolas participantes, foi realizado um sorteio entre todas as escolas municipais, que totalizavam 957 escolares matriculados no corrente ano. Para o procedimento de sorteio, foi excluída a escola estadual, em virtude de a alimentação escolar fornecida não ser municipalizada, o que inviabilizaria a realização do teste. Foram sorteadas uma escola de maior e outra de menor porte. O número de escolares das duas escolas sorteadas incluídos no estudo foi definido de acordo com a recomendação de Lanzillotti e Lanzillotti (1999). Após o sorteio, foi entregue para os responsáveis das instituições uma cartilha com explicações e objetivos do estudo, além da realização da padronização da aplicação do teste.

O teste de aceitabilidade é um conjunto de procedimentos, com metodologia definida, que, observando parâmetros técnicos, científicos e sensoriais reconhecidos, mede o índice de aceitabilidade para alimentos e preparos dos cardápios da alimentação escolar (BRASIL, 2009b; CECANE, 2010). Entre os métodos sensoriais afetivos de aceitação recomendados para o PNAE, utiliza-se o teste com escala hedônica, instrumento validado, o qual consiste na avaliação de um produto - no caso, o cardápio - a partir de uma escala gradativa, com pontos que representam psicologicamente a aceitação do escolar (SOUZA, 2007; BRASIL, 2009b, 2013; CECANE, 2010).

Para a aplicabilidade do instrumento em todas as séries, foram confeccionadas cartelas utilizando as formas verbal e facial, em que o escolar apontava sua opinião selecionando uma cartela e colocando-a em uma urna disposta dentro do refeitório após sua refeição, que era transcorrida durante o recreio. Nestas avaliações, o escolar votava no "gostei extremamente", se o cardápio estava ótimo; no "gostei moderadamente", se o cardápio estava bom; no "nem gostei/nem desgostei", se o cardápio se mostrava regular; no "desgostei moderadamente", se o cardápio estava ruim; e "desgostei extremamente", se o cardápio era muito ruim.

O nutricionista explicou, para todas as turmas da escola, nos turnos da manhã e da tarde, como seria a aplicação do teste e como cada um deveria participar da votação; realizou também o treinamento das merendeiras, para a anotação diária dos resultados da urna, e dos diretores das duas escolas, para a supervisão no decorrer da aplicação do teste. A avaliação foi realizada durante os meses de julho a setembro de 2010, sendo que a escola de menor porte aplicou o teste durante 16 dias e a de grande porte, durante 13 dias letivos alternados.

Após o término do recreio, a merendeira responsável pela alimentação da escola abria a urna e realizava a contagem das fichas de acordo com a escala, preenchendo a planilha de resultados do teste de aceitabilidade. Neste momento, foram coletadas informações referentes a número de refeições servidas no dia, número de escolares que consumiram a refeição e número de escolares presentes na escola. O nutricionista responsável e os diretores das escolas participaram durante a coleta dos dados para evitar que cada escolar pudesse votar duplamente e ainda estimulavam a participação individual com base na aceitabilidade da refeição servida.

Após a coleta dos dados, foram analisados os índices de adesão e de aceitação.

Índice de Adesão - o cálculo de adesão ao cardápio do dia foi realizado utilizando-se a proporção: número de alunos que consumiram a refeição multiplicado por 100, dividido pelo número de alunos presentes na escola. Como ponto de corte do índice de adesão, considerou-se o percentual mínimo de 85\% como indicativo de boa adesão do cardápio (CECANE, 2010). Foi considerada, como índice de recusa do cardápio, a porcentagem dos alunos que estavam na escola no dia da aplicação do teste e não realizaram a refeição.

Índice de Aceitação - o cálculo de aceitação dos alunos em relação ao cardápio do dia foi realizado a partir da soma dos votos das cartelas "gostei extremamente" e "gostei moderadamente" multiplicada por 100 e dividida pelo número de alunos que realizaram a refeição. Considerou-se o percentual mínimo de 85\% como ponto de corte indicativo de boa aceitação do cardápio do dia oferecido na escola (CECANE, 2010).

Durante os meses em que a pesquisa foi realizada, os cardápios servidos nas escolas foram diversos e sem preparações repetidas, com três opções de refeição salgada e duas opções de lanches, em cada semana. Ambas as escolas receberam e executaram o mesmo cardápio, elaborado mensalmente pelo nutricionista responsável técnico do local. Assim, para realizar a comparação entre os cardápios, estes foram definidos como lanches e refeições. As preparações compostas por pães, bolos, sanduíches, sucos, sobremesas, leites e frutas foram definidas como lanches e as preparações salgadas (arroz, feijão, polenta, legumes, macarrão, carnes) definidas como 
refeições. Além disso, foi possível comparar as médias dos índices na amostra total e entre as escolas.

O projeto foi aprovado pela Prefeitura Municipal de Barão do Triunfo-RS. Os pais ou responsáveis assinaram o Termo de Consentimento Livre e Esclarecido, e para a realização do estudo, o Comitê de Ética em Pesquisa com Seres Humanos da Escola Superior de Educação Física, da Universidade Federal de Pelotas, aprovou previamente o projeto (n. $\left.{ }^{\circ} 068 / 2009\right)$.

Os dados coletados foram digitados no Programa Excel (Microsoft Corp., USA), 2007. Para a análise dos resultados, foram utilizados os dados totais e separados pelas escolas (de menor e maior porte), e os cardápios foram divididos em lanches e refeições. Primeiramente, foram realizadas análises de frequência das variáveis da escala hedônica e de média dos índices de acordo com as escolas estudadas. Após estas análises, os dados foram submetidos à análise de variância (Anova) no Statistic 7.0, sendo que as médias foram comparadas por meio do teste de Tukey, em nível de 5\% de probabilidade.

\section{Resultados e discussão}

Dentre os 957 escolares matriculados na rede municipal de ensino, nas modalidades série inicial, final e pré-escola, 240 (25,1\%) participaram da pesquisa. Na escola de menor porte, dos 42 escolares matriculados, 40 participaram da pesquisa, com a idade variando entre 6 e 11 anos. Na escola de maior porte, dos 212 escolares matriculados, 200 realizaram a votação, com a idade entre 5 e 14 anos. Houve 5,5\% de perda de alunos em relação aos matriculados nas escolas incluídas no estudo.

A participação dos escolares no teste foi de 95,2\% na escola de menor porte e de $94,3 \%$, na de maior porte.
O estudo avaliou a aceitação dos cardápios através da frequência de votação da escala hedônica, sendo que $56,32 \%$ dos alunos gostaram extremamente da alimentação escolar e 22,42\% gostaram moderadamente. A Figura 1 mostra a frequência de pontuação total na escala hedônica. De acordo com as escolas, a de menor porte mostrou que $82 \%$ dos votos na escala foram para a opção "gostei extremamente" e 10\%, para a opção "gostei moderadamente" dos cardápios. Na escola de maior porte, 52\% dos votos marcaram a opção "gostei extremamente" e 25\%, a opção "gostei moderadamente" dos cardápios.

Quando se fez uma análise descritiva da adesão, percebeu-se que dois cardápios obtiveram 100\% de adesão na escola de menor porte: 1) Sanduíche de queijo e mortadela, e leite com achocolatado; 2) Pão com doce de leite ou bolo de aveia, e leite com achocolatado. Na escola de maior porte, a preparação 'Arroz doce com canela, e bergamota' obteve este mesmo percentual de adesão.

Em relação à aceitação dos alunos quanto aos cardápios, a escola de menor porte mostrou os seguintes cardápios com 100\% de aceitação: 1) Pão com doce de leite ou bolo de aveia, e leite com achocolatado; 2) Biscoito doce e leite com achocolatado; 3) Purê de batatas, carne com molho sugo e salada de alface; 4) Sagu de laranja e biscoito doce; 4) Bolo nega maluca e vitamina de frutas; 5) Sagu com leite e biscoito salgado. Já na escola de maior porte, nenhum cardápio obteve 100\% de aceitação.

Dos 13 cardápios servidos na escola de maior porte, sete obtiveram baixa adesão e oito mostraram baixa aceitação dos alunos. Já na escola de menor porte, dos 16 cardápios avaliados, quatro obtiveram baixa adesão dos alunos e todos obtiveram uma boa aceitação.

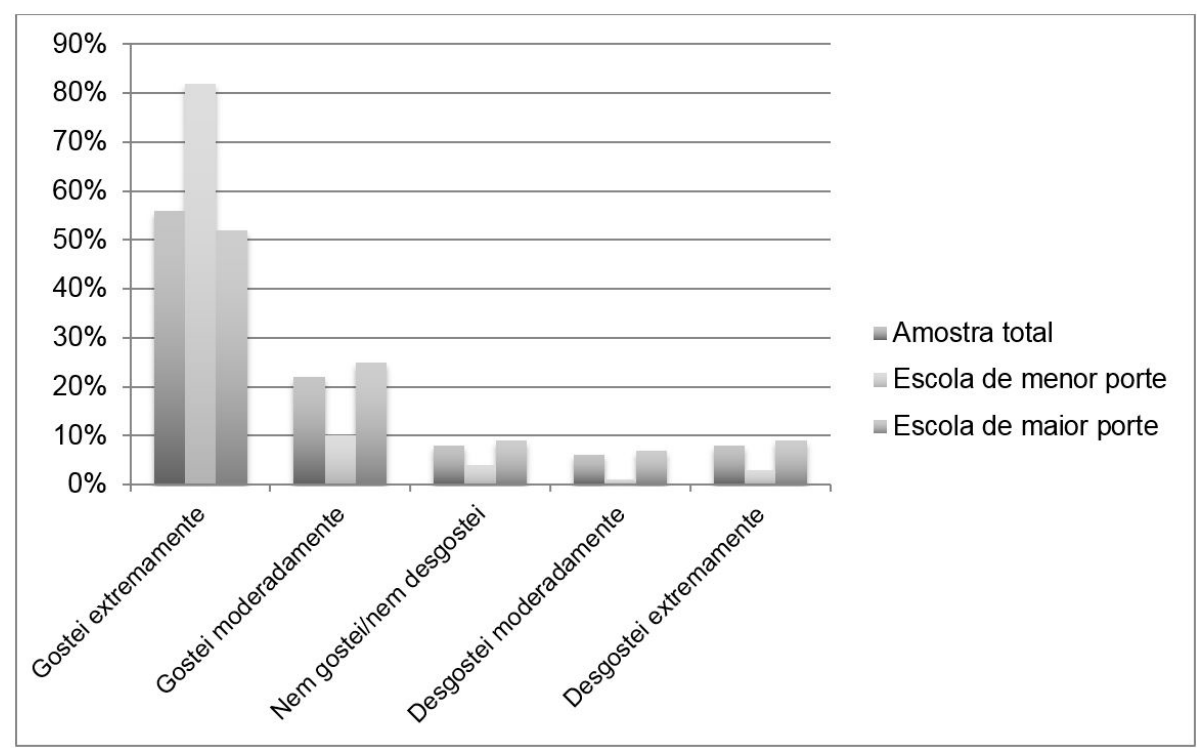

Figura 1. Frequência de pontuação total na escala hedônica de acordo com as escolas avaliadas e a amostra total, 2010. Barão do Triunfo/ RS/ Brasil, 2010. 
Após cálculos dos índices, a média total de adesão aos cardápios nas escolas foi de 86,44\% (DP \pm 9,02) e de aceitação dos escolares, em relação aos cardápios, foi de 90,64\% (DP \pm 8,79). Ao comparar a média dos índices por escola, observou-se diferença significativa em relação à aceitação dos alunos entre as escolas analisadas (Tabela 1).

Com relação à análise comparativa entre os cardápios, os lanches obtiveram médias significativamente maiores tanto no índice de adesão quanto no de aceitação, quando comparados às refeições (Tabela 2).

A Tabela 3 mostra que a aceitação dos escolares em relação aos cardápios da alimentação escolar foi maior na escola de menor porte em relação à de maior porte, quando comparadas as preparações lanche e refeição. Diversamente, a adesão aos cardápios não mostrou diferença significativa entre as escolas.

A amostra estudada está em conformidade com a recomendação de tamanho de amostra para a realização do teste de aceitabilidade (BRASIL, 2009b). Além disso, representa $25,08 \%$ da população escolar da Rede Municipal de Ensino do Município de Barão do Triunfo-RS.

Devido à crescente preocupação mundial com a promoção da alimentação saudável (WHO, 2010; BRASIL,
2012), os alimentos servidos aos estudantes têm importância fundamental. Diante disso, foi reformulada a legislação que dispõe sobre o Programa Nacional de Alimentação Escolar, alterando o valor do repasse financeiro aos municípios, incentivando a compra da agricultura familiar e, acima de tudo, visando à distribuição de uma alimentação saudável e adequada, de acordo com a faixa etária e o estado de saúde do escolar (BRASIL, 2009a, 2013).

Partindo-se desta inovação benéfica ao escolar, o teste de aceitabilidade veio em busca de melhorar a qualidade da alimentação oferecida aos escolares. Nesta pesquisa, a frequência total de aceitação na escala hedônica foi superior ao estudo realizado em Goiânia, por Vieira et al. (2006), que mostrou que apenas 6,7\% dos escolares gostaram extremamente da merenda. Estudos confirmando os achados de diferentes percentuais de aceitação, de acordo com a preparação servida no dia, estão documentados na literatura (CONRADO; NOVELLO, 2007; MATIHARA et al., 2010).

Os cardápios servidos durante a aplicação do teste foram diferentes, o que impossibilitou a comparação entre os índices; por isso, foi decidido utilizar as médias dos índices na amostra geral e entre as escolas. A diferença apresentada entre as escolas quanto ao

Tabela 1. Média e desvio padrão de adesão aos cardápios e aceitação dos alunos de acordo com a escola, na cidade de Barão do Triunfo-RS, Brasil (2010).

\begin{tabular}{lcccccc}
\multirow{2}{*}{ Escola } & \multicolumn{2}{c}{ Adesão aos cardápios } & & \multicolumn{2}{c}{ Aceitação dos alunos } \\
\cline { 2 - 3 } \cline { 5 - 6 } Menor porte & Média (\%) & Desvio Padrão & & Média (\%) & Desvio Padrão \\
Maior porte & 88,70 & 8,23 & 9,47 & $96,17^{*}$ & 4,13 \\
Total & 83,65 & 86,44 & & & $83,83^{*}$ & 8,24 \\
\hline
\end{tabular}

*Medias na mesma coluna diferem entre si pelo Teste de Tukey $(p<0,05)$.

Tabela 2. Média e desvio padrão de adesão aos cardápios e aceitação dos alunos de acordo com as preparações servidas nas escolas estudadas de Barão do Triunfo-RS, Brasil (2010).

\begin{tabular}{|c|c|c|c|c|c|}
\hline \multirow{2}{*}{ Tipo de cardápio } & \multirow{2}{*}{$\begin{array}{c}\text { Total } \\
\mathbf{n}\end{array}$} & \multicolumn{2}{|c|}{ Adesão aos cardápios } & \multicolumn{2}{|c|}{ Aceitação dos escolares } \\
\hline & & Média (\%) & Desvio Padrão & Média (\%) & Desvio Padrão \\
\hline Lanches & 16 & $90,08^{*}$ & 6,83 & $93,68^{*}$ & 5,88 \\
\hline Refeição & 13 & $81,96^{*}$ & 9,59 & $86,88^{*}$ & 10,46 \\
\hline
\end{tabular}

${ }^{*}$ Medias na mesma coluna diferem entre si pelo Teste de Tukey $(p<0,05)$.

Tabela 3. Média e desvio padrão de adesão aos cardápios e aceitação dos escolares de acordo com as preparações servidas nas escolas estudadas de Barão do Triunfo-RS, Brasil (2010).

\begin{tabular}{|c|c|c|c|c|c|c|}
\hline \multirow{2}{*}{ Tipo de cardápio } & \multicolumn{3}{|c|}{ Adesão aos cardápios } & \multicolumn{3}{|c|}{ Aceitação dos escolares } \\
\hline & Média & Desvio Padrão & & Média & Desvio Padrão & \\
\hline \multicolumn{7}{|l|}{ Lanche } \\
\hline Escola de menor porte & 92,48 & 5,24 & $p>0,06$ & 96,19 & 4,46 & $p<0,02^{*}$ \\
\hline Escola de maior porte & 86,08 & 7,38 & & 89,51 & 5,52 & \\
\hline \multicolumn{7}{|l|}{ Refeição } \\
\hline Escola de menor porte & 82,42 & 7,78 & $p>0,88$ & 96,12 & 3,09 & $\mathrm{p}<0,001^{*}$ \\
\hline Escola de maior porte & 81,57 & 10,27 & & 78,95 & 6,57 & \\
\hline
\end{tabular}

*Análise de variância (Anova). 
índice de aceitabilidade dos escolares foi significativa, resultado também encontrado no estudo de Brandão (2000), realizado em escolas municipais de Campinas-SP. Diversamente, em outro estudo, foi observada uma maior adesão à alimentação escolar nas escolas da zona urbana (CHAVES et al., 2008). Estudo recente com escolares da rede estadual de ensino de Minas Gerais apresentou aceitação de $28,8 \%$ e adesão de $45,1 \%$ às refeições servidas (SILVA et al., 2013).

Praticamente, inexistem estudos que utilizam a recomendação atual do FNDE para avaliar o índice de aceitação dos cardápios. Por isso, para a discussão dos resultados, foram utilizados estudos com metodologias similares (CHAVES et al., 2008; BLEIL et al., 2009).

A comparação entre os cardápios foi possível devido ao agrupamento das preparações descritas como lanches e refeição. Os lanches servidos apresentaram maiores adesão e aceitação do que as refeições. Mainardi (2005) constatou que nem todos os escolares realizam as refeições café da manhã e almoço, utilizando os lanches como preferência alimentar. Carneiro (2003) confirmou esta preferência alimentar das crianças por lanches em substituição à comida tradicional. Estudo de revisão constatou preferência ora por lanches, ora por refeição (OLIVEIRA; VASSIMON, 2012). Escolares em programa de alimentação italiano demostraram preferência por sobremesas e lanches na escola (TURCONI et al., 2013).

Lanches foram preferidos às refeições salgadas em estudo que analisou cardápio semanal servido numa escola municipal de ensino fundamental da cidade de Lauro de Freitas-BA (SOUZA; MAMEDE, 2010). Estudo de Cruz et al. (2013), realizado com escolares do primeiro ao quinto ano do ensino fundamental da rede municipal urbana, apontou que a aceitação maior, dentre os cardápios, foi de bolo de bacia e suco, demonstrando que há preferência por alimentos doces e industrializados em vez de preparações ricas em verduras e legumes, como a sopa.

Porém, o maior consumo de lanches proporciona elevada concentração de gorduras e carboidratos simples aos estudantes, quando comparado ao consumo de refeições completas. Além disso, pode acarretar maior incidência de cáries dentárias e aumentar a prevalência de obesidade (MATIHARA et al., 2010). Há preocupação em possibilitar a oferta de alimentos que tenham uma boa adesão entre os escolares, mas que estes venham ao encontro do emprego da alimentação saudável e adequada nas escolas, o que é fundamental para o crescimento e o desenvolvimento dos escolares, e para a melhoria do rendimento escolar (MARTINS et al., 2004). Essa premissa é tão importante que autores revelam que a aceitação da alimentação escolar mostrou-se positivamente influenciada pelas ações de Educação Alimentar e Nutricional (SILVA et al., 2013).

Além disso, os ambientes alimentares não saudáveis, como cantinas escolares, podem induzir ao consumo de alimentos com alto grau de processamento e baixo valor nutricional, os chamados ultraprocessados. A tendência de aceitação maior destes alimentos entre crianças e adolescentes brasileiros reflete o atual quadro epidemiológico e nutricional do país (SPARRENBERGER et al., 2015). Cabe ressaltar que um dos fatores que estimulam a preferência por esses alimentos é a publicidade de alimentos não saudáveis direcionada às crianças e aos adolescentes, induzindo ao comportamento de compra e de consumo (MONTEIRO; CASTRO, 2009; HENRIQUES et al., 2012; UEDA et al., 2014). Por exemplo, um estudo com crianças de 3 a 8 anos do Texas, que avaliou a influência da publicidade nas suas escolhas alimentares e o incentivo dos pais na escolha de alimentos saudáveis ou por eles preferidos. Autores verificaram que as crianças eram mais propensas a escolher o item anunciado, apesar da intervenção dos pais (FERGUSON et al., 2012).

Quando avaliadas as médias por escola, a aceitação dos escolares se manteve maior na escola de menor porte, tanto para lanches quanto para refeições, não sendo significativa a diferença entre as médias do índice de adesão. Sugere-se que esta diferença em relação às escolas possa estar relacionada à maior proximidade dos escolares e à participação nas propostas oferecidas em ambas. Além do mais, essa variação também sugere a existência de diferenças na qualidade do serviço prestado em relação ao fornecimento da alimentação escolar em uma série de quesitos: temperatura e sabor do alimento servido, quantidade de utensílios, local e espaço de refeição, aspectos estes que interferem na aceitabilidade da refeição servida.

Diferenças culturais também podem interferir na aceitação ou na adesão à alimentação escolar. As tradições alimentares, importantes para o autorreconhecimento e a autoestima de cada grupo social, não podem ser desprezadas quando se fala de alimentação adequada. Este retorno às origens de valorização dos alimentos locais e de consumo de produtos menos industrializados vem de encontro às grandes estratégias industriais, que buscam a globalização e a introdução dos mesmos produtos em todos os mercados ao redor do mundo, bem como gera confronto com as tendências da população de utilizar cada vez mais produtos "fáceis de preparar" e que demandem menos trabalho na cozinha, ou seja, alimentos, cada vez mais, com algum grau de processamento (NITZKE et al., 2012). Diante disso, as bases legais do PNAE propõem a promoção de hábitos alimentares mais saudáveis, com respeito à cultura alimentar, com o intuito de melhorar o panorama epidemiológico atual dos escolares, além de aproximar a alimentação da escola com a agricultura familiar (TEO; MONTEIRO, 2012).

Nesse sentido, sugere-se que as preparações oferecidas às crianças devem ser apresentadas de uma maneira atrativa, objetivando aumentar o grau de 
Adesão e aceitabilidade de cardápios da alimentação escolar do ensino fundamental de escolas de zona rural Raphaelli, C. O. et al.

aceitação e de adesão dos escolares, para contribuir para a formação de hábitos alimentares saudáveis (MUNIZ; CARVALHO, 2007)

Algumas limitações devem ser consideradas nesta pesquisa. Primeiramente, o levantamento de dados de nível socioeconômico dos alunos não foi realizado, podendo ter influenciado na comparação dos índices entre as escolas. Em segundo lugar, os dados de idades dos escolares são mostrados apenas em faixas etárias nas características de cada escola, não sendo utilizados, nas análises, em vista da falta de coleta desta variável e isso pode interferir, pois, o escolar pode ter hábitos alimentares diferentes conforme cada faixa etária. Em terceiro lugar, a limitação em relação ao preparo da alimentação escolar, à temperatura da refeição, além da aparência e do sabor dos alimentos, aspectos que poderiam interferir nos resultados por conter diferenças - que não foram elencadas - entre as escolas.

\section{Conclusões}

Concluindo, o índice de aceitabilidade e a aceitação dos escolares em relação aos cardápios mostraram-se adequados nas duas escolas de zona rural, sendo que houve diferença nos resultados de acordo com o porte da instituição e o tipo de preparação servida.

Estudos na área de alimentação escolar devem ser realizados e as análises dos índices de adesão e de aceitação mostram-se importantes, para que sejam adotadas conforme a recomendação do PNAE e, consequentemente, possibilitar melhor comparação. Além disso, pela escassez de estudos a respeito da aceitabilidade das refeições servidas aos escolares, este estudo pode contribuir para subsidiar pesquisas futuras nesta área, bem como auxiliar na identificação dos motivos da rejeição da alimentação escolar, a fim de evitar o desperdício de recursos financeiros, de alimentos e mão de obra, e de garantir o fornecimento de refeições balanceadas nutricionalmente. Estimula-se, também, a real inclusão da educação alimentar e nutricional no currículo escolar, abordando os temas alimentação e nutrição, e o desenvolvimento de práticas saudáveis de alimentação na perspectiva da segurança alimentar e nutricional, para que, assim, a alimentação servida nas escolas possa ser satisfatoriamente consumida pelos escolares (PÉREZ et al., 2004).

\section{Referências}

ABREU, M. Alimentação escolar na América Latina: programas universais ou focalizados/políticas de descentralização. Brasília: SEDIAE/INEP/MEC, 1995.

BLEIL, R. A. T.; SALAY, E.; SILVA, M. V. Adesão ao programa de alimentação escolar por alunos de instituições públicas de ensino no município de Toledo, PR. Segurança Alimentar e Nutricional, Campinas, v. 16, n. 1, p. 65-82, 2009.
BRANDÃO, T. M. Avaliação da aceitação e preferências de cardápios do Programa de Merenda Escolar em escolas municipais de ensino fundamental da cidade de Campinas. 2000. 91 f. Dissertação (Mestrado)-Universidade Estadual de Campinas, Campinas, 2000.

BRASIL. Senado Federal. Constituição da República Federativa do Brasil. Brasília, 1988.

BRASIL. Lei $n^{\circ} 11.947$, de 16 de junho de 2009. Dispõe sobre o atendimento da alimentação escolar e do Programa Dinheiro Direto na Escola aos alunos da educação básica. Diário Oficial [da] República Federativa do Brasil, Brasília, DF, 17 jun. 2009a.

BRASIL. Ministério da Educação. Fundo Nacional de Desenvolvimento da Educação. Relatório do Grupo de Trabalho: aplicabilidade do teste de aceitabilidade nos alimentos destinados ao Programa Nacional de Alimentação Escolar. Brasília, 2009b. Disponível em: <www.fnde.gov.br/alimentacaoescolar/relatoriogrupotecnicotestes/ download>. Acesso em: 20 out. 2010.

BRASIL. Ministério do Desenvolvimento Social e Combate à Fome. Secretaria Nacional de Segurança Alimentar e Nutricional. Marco de referência de educação alimentar e nutricional para as políticas públicas. Brasília, 2012.

BRASIL. Ministério da Educação. Fundo Nacional de Desenvolvimento da Educação. Resolução n 26, de 17 de junho de 2013. Dispõe sobre o atendimento da alimentação escolar aos alunos da educação básica no âmbito do Programa Nacional de Alimentação Escolar - PNAE. Diário Oficial [da] República Federativa do Brasil, Brasília, DF, 18 jun. 2013. Disponível em: <http://www. fnde.gov.br/index.php/ae-legislacao>. Acesso em: 20 abr. 2015.

BRASIL. Ministério da Educação. Fundo Nacional de Desenvolvimento da Educação. Dados estatísticos PNAE. Brasília, 2016. Disponível em: <http://www.fnde.gov.br/index.php/ae-dados-estatisticos>. Acesso em: 25 out. 2016.

CARNEIRO, H. Comida e sociedade: uma história da alimentação. Rio de Janeiro: Campus, 2003.

CENTRO COLABORADOR EM ALIMENTAÇÃO E NUTRIÇÃO ESCOLAR - CECANE. Manual para aplicação dos testes de aceitabilidade no Programa Nacional de Alimentação Escolar - PNAE. São Paulo: Unifesp, 2010.

CERVATO-MANCUSO, A. M.; WESTPHAL, M. F.; ARAKI, E. L.; BÓGUS, C. M. School feeding programs' role in forming eating habits. Revista Paulista de Pediatria, São Paulo, v. 31, n. 3, p. 324-330, 2013. PMid:24142314. http://dx.doi.org/10.1590/ S0103-05822013000300008.

CHAVES, M. G. A. M.; MARQUES, C. M. H.; DALPRA, J. O.; RODRIGUES, P. A.; CARVALHO, M. F.; CARVALHO, R. F. Estudo da relação entre a alimentação escolar e a obesidade. HU Revista, Juiz de Fora, v. 34, n. 3, p. 191-197, 2008.

CONRADO, S.; NOVELLO, D. Aceitação e análise nutricional de merenda escolar por alunos da rede municipal de ensino. Revista Eletrônica Lato Sensu, Curitiba, v. 2, n. 1, p. 1-15, 2007. 
Adesão e aceitabilidade de cardápios da alimentação escolar do ensino fundamental de escolas de zona rural Raphaelli, C. O. et al.

CRUZ, L. D.; SANTOS, A. J. A. O.; SANTOS, A. A. O.; GOMES, A. B. L.; ANDRADE, F. A. M.; MARCELLINI, P. S. Análise de aceitação da alimentação escolar dos alunos das escolas municipais urbanas de Itabaiana-SE. Scientia Plena, Sergipe, v. 9, n. 10, p. 1042031-1042036, 2013.

FERGUSON, C. J.; MUÑOZ, M. E.; MEDRANO, M. R. Advertising influences on young children's food choices and parental influence. Jornal de Pediatria, Rio de Janeiro, v. 160, n. 3 , p. 452-455, 2012. PMid:21983204. http://dx.doi.org/10.1016/j. jpeds.2011.08.023.

HENRIQUES, P.; SALLY, E. O.; BURLANDY, L.; BEILER, R. M. Regulamentação da propaganda de alimentos infantis como estratégia para a promoção da saúde. Ciência \& Saúde Coletiva, Rio de Janeiro, v. 17, n. 2, p. 481-490, 2012. http:// dx.doi.org/10.1590/S1413-81232012000200021

INSTITUTO BRASILEIRO DE GEOGRAFIA E ESTATÍSTICA - IBGE. Censo demográfico 2007. Rio de Janeiro, 2010. Disponível em: <http://www.ibge.gov.br/cidadesat/painel/painel. php?codmun=430175\#>. Acesso em: 10 fev. 2010.

INSTITUTO NACIONAL DE PESQUISAS E ESTUDOS ANÍSIO TEIXEIRA - INEP. Censo escolar 2009. Brasília, 2009. Disponível em: <http://www.educacenso.inep.gov.br>. Acesso em: 10 fev. 2010.

LANZILLOTTI, R. S.; LANZILLOTTI, H. S. Análise sensorial sob o enfoque da decisão fuzzy. Revista de Nutrição, Campinas, v. 12 , n. 2, p. 145-157, 1999. http://dx.doi.org/10.1590/S141552731999000200004

MAINARDI, N. A ingestão de alimentos e as orientações da escola sobre alimentação, sob o ponto de vista do aluno concluinte do ensino fundamental. 2005. 151 f. Dissertação (Mestrado)-Universidade de São Paulo, Piracicaba, 2005.

MARTINS, R. C. B.; MEDEIROS, M. A. T.; RAGONHA, G. M.; OLBI, J. H.; SEGATTI, M. E. P.; OSELE, M. R. Aceitabilidade da alimentação escolar no ensino público fundamental. Saúde em Revista, Piracicaba, v. 6, n. 13, p. 71-78, 2004.

MATIHARA, C. H.; TREVISANI, T. S.; GARUTTI, S. Valor nutricional da merenda escolar e sua aceitabilidade. Saúde e Pesquisa, Maringá, v. 3, n. 1, p. 71-77, 2010.

MONTEIRO, C. A.; CASTRO, I. R. R. Porque é necessário regulamentar a publicidade de alimentos. Ciência e Cultura, Campinas, v. 61, n. 4, p. 56-59, 2009.

MUNIZ, V. M.; CARVALHO, A. T. O Programa Nacional de Alimentação Escolar em município do estado da Paraíba: um estudo sob o olhar dos beneficiários do Programa. Revista de Nutrição, Campinas, v. 20, n. 3, p. 285-296, 2007. http://dx. doi. org/10.1590/S1415-52732007000300007

NITZKE, J. A.; THYS, R.; MARTINELLI, S.; OLIVEIRAS, L. Y.; AUGUSTO-RUIZ, W.; PENNA, N. G.; NOLL, I. B. Segurança alimentar: retorno às origens? Brazilian Journal of Food
Technology, Campinas, v. 15, p. 2-10, 2012. http://dx.doi. org/10.1590/S1981-67232012005000044

OLIVEIRA, M. C.; VASSIMON, H. S. Programa nacional de alimentação escolar e sua aceitação pelos alunos: uma revisão sistemática. Investigação, Franca, v. 12, p. 4-10, 2012.

PEIXINHO, A. M. L. A trajetória do Programa Nacional de Alimentação Escolar no período de 2003-2010: relato do gestor nacional. Ciência \& Saúde Coletiva, Rio de Janeiro, v. 18, n. 4, p. 909-916, 2013. PMid:23670366. http://dx.doi.org/10.1590/ S1413-81232013000400002.

PÉREZ, R. C.; ARANCETA, J.; BRUG, H.; WIND, M.; HILDONEN, C.; KLEPP, K. P. Estratégias educativas para la promoción del consumo de frutas y verduras e nel médio escolar: proyecto pro children. ALAN, [S.I.], v. 54, p. 14-19, 2004. Suplemento 1.

RAMOS, M. O. "As crianças estão se sentindo importantes": avanços na alimentação escolar a partir da Lei 11947/2009 e da compra da agricultura familiar. Revista Trajetória Multicursos, Osório, v. 4, n. 29, p. 4-29, 2011.

SIDANER, E.; BALABAN, D.; BURLANDY, L. The Brazilian school feeding programme: an example of an integrated programme in support of food and nutrition security. Public Health Nutrition, Wallingford, v. 16, n. 6, p. 989-994, 2013. PMid:23218237. http:// dx.doi.org/10.1017/S1368980012005101.

SILVA, C. A. M.; MARQUES, L. A.; BONOMO, E.; BEZERRA, O. M. P. A.; CORRÊA, M. S.; PASSOS, L. S. F.; SOUZA, A. A.; BARROS, B. F.; SOUZA, D. M. S.; REIS, J. A.; ANDRADE, N. G. O Programa Nacional de Alimentação Escolar sob a ótica dos alunos da rede estadual de ensino de Minas Gerais, Brasil. Ciência \& Saúde Coletiva, Rio de Janeiro, v. 18, n. 4, p. 963-969, 2013. http:// dx.doi.org/10.1590/S1413-81232013000400008.

SOUSA, A. A.; SILVA, A. P. F.; AZEVEDO, E.; RAMOS, M. O. Cardápios e sustentabilidade: ensaio sobre as diretrizes do Programa Nacional de Alimentação Escolar. Revista de Nutrição, Campinas, v. 28, n. 2, p. 217-229, 2015. http://dx.doi. org/10.1590/1415-52732015000200010.

SOUZA, A. L. C.; MAMEDE, M. E. O. Estudo sensorial e nutricional da merenda escolar de uma escola da cidade de Lauro de Freitas-BA. Revista do Instituto Adolfo Lutz, São Paulo, v. 69, n. 2, p. 255-260, 2010.

SOUZA, L. F. Avaliação de ponto de corte para índice de aceitabilidade de produtos alimentícios e preparações no âmbito do Programa Nacional de Alimentação Escolar: uma metanálise. Brasília: [s.n.], 2007.

SPARRENBERGER, K.; FRIEDRICH, R. R.; SCHIFFNER, M. D.; SCHUCH, I.; WAGNER, M. B. Consumo de alimentos ultraprocessados entre crianças de uma Unidade Básica de Saúde. Jornal de Pediatria, Rio de Janeiro, v. 91, n. 6, p. 535-542, 2015. PMid:26092227. http://dx.doi.org/10.1016/j. jped.2015.01.007.

SPINELLI, M. A. S.; CANESQUI, A. M. O Programa de Alimentação Escolar no Estado de Mato Grosso: da centralização à 
Adesão e aceitabilidade de cardápios da alimentação escolar do ensino fundamental de escolas de zona rural

Raphaelli, C. O. et al.

descentralização (1979-1995). Revista de Nutrição, Campinas, v. 15, n. 1, p. 105-117, 2002. http://dx.doi.org/10.1590/S141552732002000100011.

SULLIVAN, S. A.; BIRCH, L. L. Infant dietary experience and acceptance of solid foods. Pediatrics, Springfield, v. 93, n. 2, p. 271-277, 1994. PMid:8121740.

TEO, C. R. P. A.; MONTEIRO, C. A. Marco legal do Programa Nacional de Alimentação Escolar: uma releitura para alinhar propósitos e prática na aquisição de alimentos. Revista de Nutrição, Campinas, v. 25, n. 5, p. 657-668, 2012.

TURCONI, G.; TESTA, L.; MORO, S.; ROSSI, M.; ROGGI, C., MACCARINI, L. Acceptability, waste and nutritional adequacy of primary school canteen menus: an observational study in Pavia, Northern Italy. Journal of Nutrition \& Food Sciences, Sunnyvale, v. 3, n. 238, p. 1-6, 2013.

UEDA, M. H.; PORTO, R. B.; VASCONCELOS, L. A. Publicidade de alimentos e escolhas alimentares de crianças. Psicologia:
Teoria e Pesquisa, Brasília, v. 30, n. 1, p. 53-61, 2014. http:// dx.doi.org/10.1590/S0102-37722014000100007.

VIEIRA, P. S.; MORAES, I. C.; PIZARRO, J. C.; PARREIRA, M. A. Aceitabilidade e qualidade da merenda escolar: um estudo de caso. In: ENCONTRO NACIONAL DE ESTUDANTES DE EDUCAÇÃO FíSICA, 27., 2006, Goiânia. Anais... Rio de Janeiro: ENEEF, 2006.

WALTER, B.; CHAIM, N. A. O programa nacional de alimentação escolar e a gestão municipal: eficiência administrativa, controle social e desenvolvimento local. Revista de Nutrição, Campinas, v. 22, n. 5, p. 595-607, 2009. http://dx.doi.org/10.1590/S141552732009000500001.

WORLD HEALTH ORGANIZATION - WHO. Global strategy on diet, physical activity and health. In: WORLD HEALTH ASSEMBLY, 57., 2010, Geneva. Proceedings... Geneva, 2010. Disponível em: <www.who.int/gb/ebwha/pdf_files/WHA57/A57_R17-en. pdf>. Acesso em: 20 out. 2010. 